\title{
The relationship between oxidative stress and thyroid autoantibodies in patients with Hashimoto s thyroiditis.
}

$\underline{\text { İhsan Ates }}{ }^{1}$, Fatma Meriç Y1lmaz ${ }^{2}$, Mustafa Altay ${ }^{1}$, Canan Topçuoğlu ${ }^{2}$, Nisbet Yılmaz ${ }^{1}$, Serdar Güler ${ }^{3}$

${ }^{1}$ Ankara Numune Education and Research Hospital, Department of Internal Medicine, Ankara, Turkey

${ }^{2}$ Ankara Numune Education and Research Hospital, Department of Biochemistry, Ankara, Turkey

${ }^{3}$ Ankara Numune Education and Research Hospital, Department of Endocrinology and Metabolism, Ankara, Turkey

\section{Objectives:}

\section{Methods:}

\section{Results:}

Conclusions:

This study examined numerous parameters of OS according to HT stages. The findings provide a general picture of how OS might be affected by thyroid hormone and thyroid autoantibody levels in patients with $\mathrm{HT}$.

The relationship between Hashimoto's thyroiditis $(\mathrm{HT})$ and oxidative stress $(\mathrm{OS})$ has been investigated in several studies that have included a limited number of patients, the findings have not been conclusive, which indicates that additional research that investigates parameters of OS in larger patient populations is needed. As such, this dissertation study aimed to determine the levels of parameters of OS and their relationship with thyroid antibodies in HT patients in the euthyroid, subclinical, and overt hypothyroidism stages.

This study included 93 treatment-naïve HT patients aged $>18$ years and 31 healthy volunteer controls with no known disease. TSH, sT4, anti-TPO, and anti-Tg were measured via ECLIA, and serum total antioxidant status (TAS), total oxidant status (TOS), total thiol (total-SH), paraoxonase (PON), and arylesterase were measured via the colorimetric method.

The TOS level and OS index (OSI) were higher in the overt hypothyroidism group than in the other group, whereas TAS, total-SH, and arylesterase levels were lower in the overt hypothyroidism group than in the other groups. Total-SH level was similar in the control and subclinical hypothyroidism groups, but was higher in the euthyroid group than in the control and subclinical hypothyroidism groups. The log (PON) and PON/HDL levels were higher in the control group than in all 3 patient groups. There weren't any significant differences in the log (PON) or PON/HDL levels between the 3 patient groups. There was a negative correlation between the anti-TPO level, and TAS, log (PON), and PON/HDL level, and between the total SH and anti-Tg levels. Overt hypothyroidism was an independent predictor of the level of all oxidative stress parameters, except for total-SH.

\section{References:}

1. Jackson S H, Devadas S, Kwon J ve ark. T cells express a phagocyte-type NADPH oxidase that is activated after T cell receptor stimulation. Nat Immunol, 2004. 5(8): s. 818-27.

2. Yilmaz S, Ozan S, Benzer F ve ark. Oxidative damage and antioxidant enzyme activities in experimental hypothyroidism. Cell Biochem Funct, 2003. 21(4): s. 325-30.

3. Baser $\mathrm{H}$, Can U, Baser $\mathrm{S}$ ve ark. Assesment of oxidative status and its association with thyroid autoantibodies in patients with euthyroid autoimmune thyroiditis. Endocrine, 2014. 